\title{
Substantiating rational parameters of a method for shrinkage ore stoping while developing thin- vein steeply inclined deposits
}

\author{
Leonid Shyrin ${ }^{1}$, Yevhenii Koroviaka ${ }^{1 *}$, Valerii Rastsvietaiev ${ }^{1}$, and Oleksandr Denyshchenko ${ }^{1}$ \\ ${ }^{1}$ National Mining University, Department of Transport Systems and Technologies, 19 Yavornytskoho \\ Ave., 49005 Dnipro, Ukraine
}

\begin{abstract}
Objective of the paper is to substantiate rational ore-stoping technique while using small wells in the context of thin-vein steeply inclined deposit mining. The technique is based upon the repeated field studies and simulation of ore drawing processes for shrinkage ore stoping in terms of the oriented drilling of periphery holes. A design of a blast-hole charge with low-density porous intermediate layer has been proposed as a result as well as a mechanism of shock-wave propagation within rock mass in the process of thin steeply inclined vein stoping. Scientific novelty is represented by means of analytical results of scientific sources, and dependences of ore losses on the vein wall hypsometry resulting from shrinkage stoping in the context of the technique being proposed. Practical relevance is to substantiate rational parameters of the ore-stoping technique being proposed. The technique involves designs of blast-hole charges with low-density porous intermediate layer in stemming. Moreover, the technique proposes to place the intermediate low-density stemming layer right after a blast hole was charged with explosives and live primers were inserted.
\end{abstract}

\section{Introduction}

Thin-vein steeply inclined deposits are something special for mining industry. The veintype deposits have been formed when earth fissures were filled with mineral substance owing to hydrothermal processes and pneumatolysis. Their features, being typical for certain deposits, experience numerous variations in the context of a level and a block involving specific analysis and consideration while selecting and substantiating alternatives of mining which may differ greatly from traditional ones [1,2].

As a rule, the extraction techniques with ore shrinkage, use of expansion-type support and worked-out area stowing applied in the process of thin-vein steeply inclined deposits mining, rely upon horizontal ore shrinkage to the rise.

Morphological characteristic and shape of ore body occurrence are important factors while selecting a technique for thin-vein deposit development. To decrease ore dilution degree, mining operations are performed along the vein only; besides, compulsory in-mine

\footnotetext{
${ }^{*}$ Corresponding author: koroviakaye@gmail.com
} 
exploration is implemented constantly for each block to evaluate operatively vein occurrence and metal content in it. When the indices decrease, mining is ceased and due to the imperfection of extraction systems being applied the reserves are frozen.

\section{Method of examination}

The field studies which have been carried out in the mine workings of Zaporizhzhia IronOre Integrated Works showed both mechanism and zones of active crushing taking place within rock mass when stress waves passed through it in the process of ore shrinkage. Moreover, they have helped forecast potential behaviour of rocks when ore bodies are mined horizontally to the rise [3].

Generally, veins occur within the mineralized rocks penetrated with folia nets. As a result, the rock mass represented by hard rocks cannot be considered as a continuum within mineralization area. Thus, when stress waves, resulting from explosion of blast-hole charges, pass through the rock mass, fissures occur and discontinuity takes place along the folia. Depth of the fissures, propagated beyond mineralization zones, can reach $1.0 \mathrm{~m}$. In the context of the repeated stress waves, passing through the rock mass, fissures width as well as formation of partings being mutually fixed blocks of a spatial form takes place. When a contact between the fixed blocks is lost and external action on the rock mass happens, then rock exfoliation in the form of plates and blocks with 0.1 to $0.6 \mathrm{~m}$ width within 0.5 to $12.0 \mathrm{~m}^{2}$ area is involved; in the context of ore drawing, it results in its additional dilution since it mixes with the broken-down rocks.

Fig. 1 demonstrates typical site of ore direction to the dip resulting from mine surveying while constructing rising and change in the dynamic axis of the face space within specific sections of I-I, II-II, III-III block (Fig. 1b).

$a$

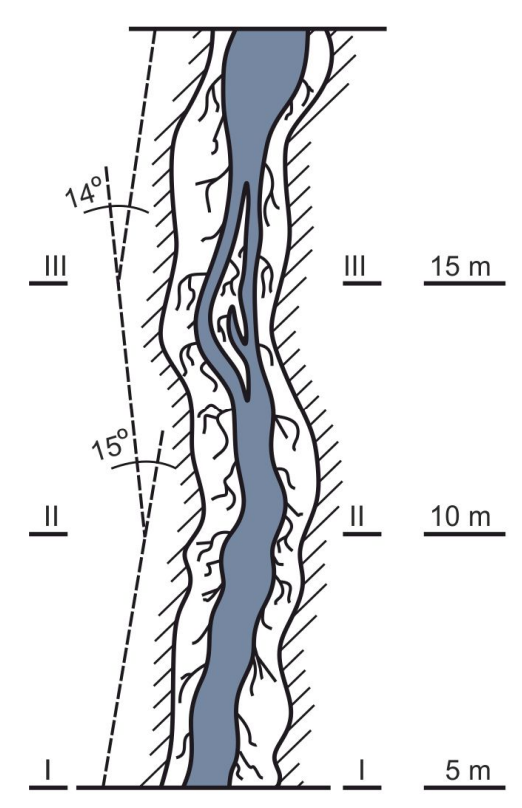

$b$

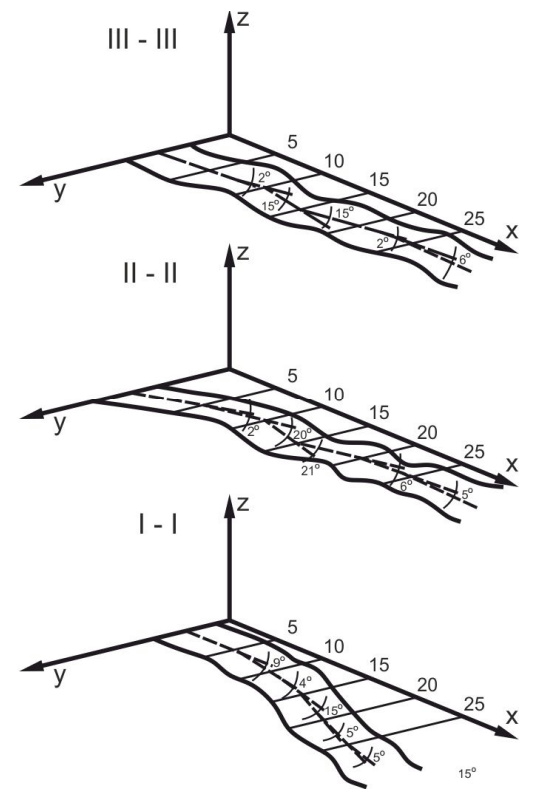

Fig. 1. Change in the dynamic axis of a stope in the process of shrinkage stoping of ore bodies: a - to the dip; b-across the pitch. 
It should be noted that due attention was not paid to the analysis of axial section of a stope walls in the process of steeply inclined veins mining. It depends on the fact that enterprises of the industry initially mined approachable sites with the stable wall rocks and large content of commercial components.

Mining deepening complicates significantly occurrence of the steeply inclined ore bodies. Extraction of the reserves involve the deposit sites where wall rocks are of mean stability or less; moreover, commercial components need measures to upgrade rock mass being mined (i.e. decreased ore dilution, selective mining etc.).

For the first time ever, such measures involved data concerning the effect of drilling and blasting on the rock mass state (i.e. wall rock fissuring, stability, and roughness).

Hypsometric plans of wall surfaces are built while using methods of statistic processing of experimental data and results of comparative evaluations with the corresponding theoretical indices (Fig. 2). Density of their isolines matches the adopted drilling and blasting parameters in terms of ore shrinkage stoping. Analysis of the hypsometric plans obtained at Zaporizhzhia Iron-Ore Integrated Works has helped determine that in the context of traditional drilling and blasting operations, the amplitude between contour figures run at the level of peaks and valleys of wall surface of the ore bodies, being extracted, is 0.3 to $0.4 \mathrm{~m}$; in some cases it reaches 0.5 to $0.55 \mathrm{~m} \mathrm{[3]}$.

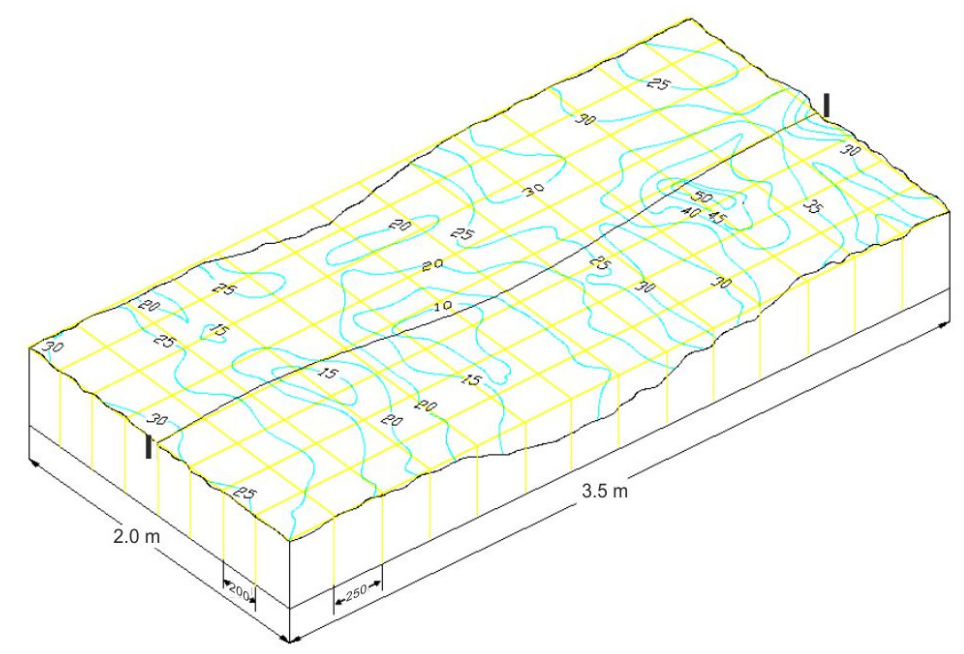

Fig. 2. Hypsometric surface of a stope walls after shrinkage stoping of ore.

It should be noted that shape of peaks and valleys depends considerably on the technological parameters of blasting and drilling as well as on physical and mechanical characteristics of rock mass being blasted.

Analysis of the developed hypsometric plans of wall surfaces of stopes of Zaporizhzhia Iron-Ore Integrated Works made it possible to state that changes in their axial sections are of stochastic nature. It has also been determined that both mining and geological as well as technological factors are involved in the formation of a stope wall contour. Physical and mechanical properties as well as their fracturing degree are among basic mining and geological factors. Following factors are the first ones among those reflecting specific character of shrinkage stoping of thin steeply inclined vein: diameter of a blast hole and its length; type of explosives used in the blast holes, their specific consumption, and concentration; arrangement of the blast holes within a stope and blasting technique etc. 
It has also been determined that amplitude of peaks of valleys of a bottom wall and upper wall of the vein stipulates cooperation of load-haul-dumpers effecting significantly the losses of ore during its drawing from blocks.

From the viewpoint of interaction between wall rocks and mining equipment operating within narrow face area of a block with unsteady hypsometry, axial sections and vertical cross-sections of top wall and bottom wall of a stope simulating morphology of ore body occurrence across the pitch are of specific interest (Fig. 1b).

From the viewpoint of determination of ore losses and nature of its overhanging while drawing from the block, axial sections and cross sections of both top and bottom walls of a stope to the dip of ore body as well as amplitude of irregularities (i.e. peaks and valleys) of the vein top wall and bottom wall are of particular interest (Fig. 3).

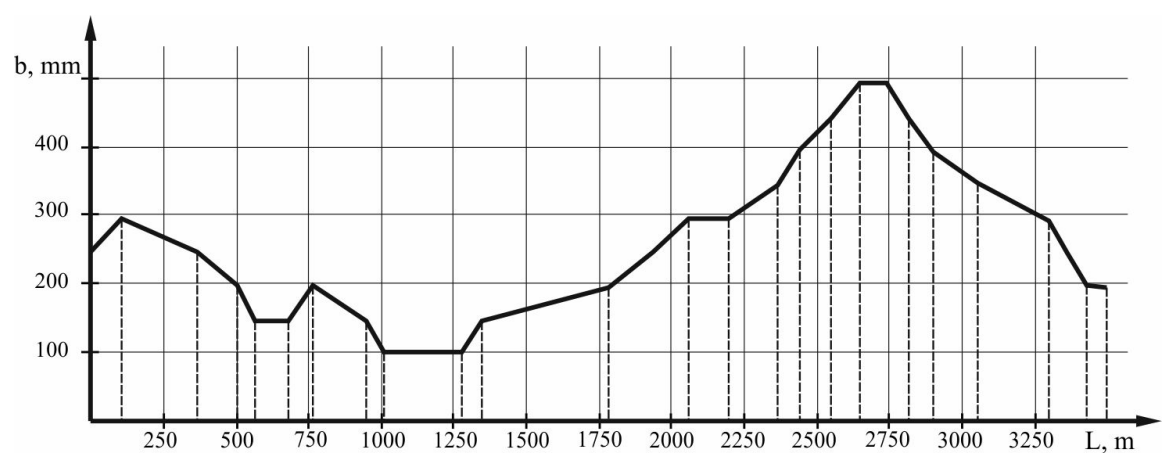

Fig. 3. Fragment of axial section of wall surfaces of the block along I-I line (Fig. 1).

Horizontal drilling-and-blasting technique, applied to the rise, is the specific feature to mine thin-vein steeply inclined deposits. The technique relies upon shrinkage stoping method making it possible to decrease ore dilution since the stope can follow the vein despite variability of its occurrence elements; it provides breaking of ore sufficient for its unrestricted drawing within narrow stoping zone; and it allows performing oriented discharge of the broken rock mass towards drawing-off level.

However, in addition to traditional techniques applied for ore breaking by means of rising blastholes, it is required to have rather stable wall rocks. Practices of thin-vein gold fields mining shows that significant ore dilution takes place when parameters of drilling and blasting operations mismatch the conditions of thin-vein deposit development.

Moreover, use of load-haul-dumpers in the context of thin-vein steeply inclined deposits mining is possible if only design parameters of drilling and blasting operations are met in full since the parameters provide optimum width of a stoping zone $m_{\text {opt }}$ and minimum irregularities of the stope walls.

Studies [4] concerning the support of design parameters of dri may achieve $\pm 30 \%$ due to irregularities of wall surfaces and variable directions of ore body occurrence. That complicates seriously the process aimed at selection and substantiation of a type of loadhaul-dumpers since minimal width and length are the basic design parameters determining their maneuverability within narrow stoping zone.

In this connection, Fig. 4 represents a scheme according to which it is proposed to determine a stoping zone width to substantiate minimal design parameters of load-hauldumpers. 


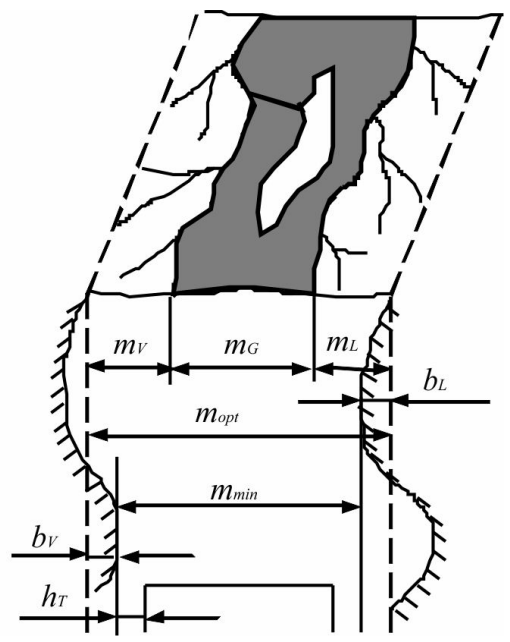

Fig. 4. A scheme to determine minimal width of a stoping zone: $m_{G}$ is ore body thickness; $m_{L}$ and $m_{V}$ are thicknesses of the undercut rocks of top wall and bottom of the vein; $m_{\text {opt }}$ is optimum width of the stoping zone; $b_{L}$ and $b_{V}$ are amplitudes between contour figures at the level of peaks and valleys of wall surfaces of the stope; $m_{\min }$ is minimum width of the stoping zone; and $h_{T}$ is technological gap.

Optimum width $m_{\text {opt }}$ involving a coefficient of thickness being mined $k_{M}$ should be considered as a minimum width of the stoping zone:

$$
m_{\text {min }}=m_{\text {opt }} \cdot k_{M} \text {. }
$$

Optimum width of the stoping zone is determined taking into consideration recommendations from [5]; the width consists of the vein thickness and thickness of wall rocks being cut. Together with mineralization degree, the thickness of wall rocks being mined is considered as total thickness of rocks of top wall and bottom wall being cut:

$$
\begin{aligned}
& m_{\text {opt }}=m_{G}+m_{P} ; \\
& m_{P}=m_{L}+m_{V} .
\end{aligned}
$$

In the context of Fig. 1, the coefficient of thickness $k_{M}$ variation coefficient is determined as:

$$
k_{M}=\frac{m_{P}}{\left(m_{P}+\frac{b_{L}+b_{V}}{2}\right) k_{G}},
$$

where $m_{P}$ is total thickness of wall rocks being cut; $b_{L}$ and $b_{V}$ are heights of the ore vein top wall and bottom wall respectively; and $k_{G}$ is hypsometric coefficient of the stope zone walls after ore breaking up by explosives.

A type of geometric (determinate) index of V.A. Bukrinski was taken as a description point to determine hypsometric coefficient [6]:

$$
k_{G}=\frac{\int d l}{L},
$$

where $\int d l$ is integral over the contact curve; and $L$ is the block width. 
Indices of the stoping zone wall irregularities are associated with traditional technique of blasthole drilling from one drill setup when ore breaking up by explosives is evaluated in terms of significant release of rock mass lumps resulting in considerable dilution of the mined ore; besides, it complicates the ore drawing, increases expenditures for its crushing in the preparation process, and makes the rock mass unstable since fissures grow deep disturbing the rock mass integrity.

To decrease losses and degree of ore dilution, oriented blast-hole drilling is recommended for future use of the mining system with ore shrinkage. Processing description of drilling and blasting operations specifies bottom drilling from using three drill setups (Fig. 5). The procedure of hole drilling is as follows: first, central hole No. 1 is run in; then the drill is displaced right (left) at the distance of $0.2-0.3 \mathrm{~m}$ with $85^{\circ}$ angle, periphery holes No. 2 and 3 are run in. According to blasting and drilling description, face area of a stope, formed in the process of ore breaking up by explosives, is characterized by minimum width and hypsometry of wall surfaces (amplitude between levels of peaks and valleys will be 0.2 to $0.25 \mathrm{~m}$ ) simulating the vein walls [7].

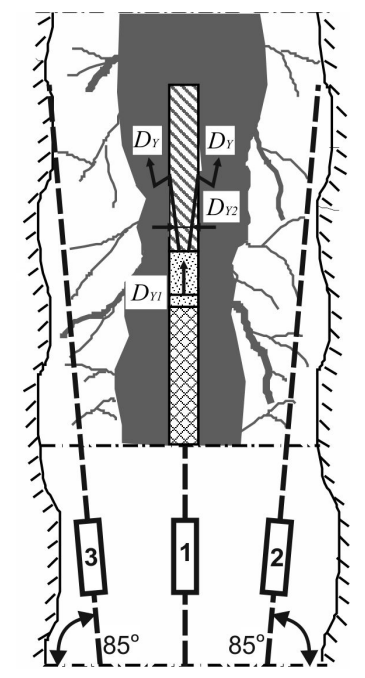

Fig. 5. Technique of ore shrinkage stoping in the context of oriented drilling of periphery holes ore breaking with schematic representation of propagation of shock waves and "compression" of lower part of tamping while blasting: $D_{Y}$ is a shock-wave front propagating within the rock mass; $D_{Y 1}$ is a shock-wave front propagating within the low-density porous layer; $D_{Y 2}$ is a shock-wave front propagating within the tamping from the borehole hole wall.

When directions of periphery holes vary, the amount of ore losses increases along with the amount of inrushes. Moreover, the mined thickness of the ore bodies as well as topography of the stope also experiences changes. If drilling directions are met strictly then optimum parameters of stoping zone and crushing of wall rocks being cut are obtained. In addition, decrease in peripheral rock disturbance is achieved resulting in the decreased degree of ore dilution.

If the oriented drilling of peripheral holes is applied, then distance between horizontals run between extreme levels of peaks and valleys is 0.2 to $0.25 \mathrm{~m}$ when the site length is $2.0 \mathrm{~m}$ to the dip, and $3.5 \mathrm{~m}$ across the pitch. Parameters of the sites being studied are substantiated: if downdip, then by means of traditional hole length in the context of shrinkage stoping of thin steeply inclined veins; across the pitch, then by means of length of load-haul-dumper St 500HE Microscoop. 


\section{Results and discussion}

The results of physical modeling of ore drawing process if shrinkage is applied have shown that ore loss amounts vary within $12-15 \%$; they depend linearly on the ore wall hypsometry reflecting substantively actual amplitudes between levels of peaks and valleys being formed in the process of shrinkage stoping of ore bodies and on the vein bedding angle; on the moisture content of ore being drawn and fraction value of the material being produced (Fig. 6).

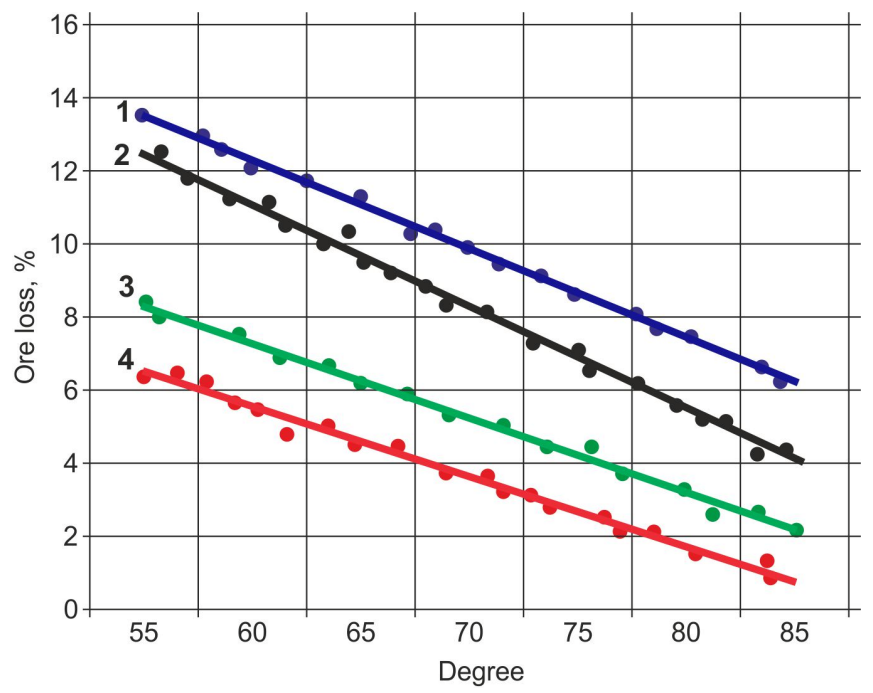

Fig. 6. Graphical dependences of changes in ore losses on the vein wall hypsometry formed as a result of shrinkage stoping of the ore drawing with 1.0 to $5.0 \mathrm{~mm}$ amplitude of peaks and valleys: $1-300-$ $400 \mathrm{~mm}$ if ore moisture is $W=10 \% ; 2-300-400 \mathrm{~mm}$ if ore moisture is $W=0 \% ; 3-200-250 \mathrm{~mm}$ if ore moisture is $W=10 \% ; 4-200-250 \mathrm{~mm}$ if ore moisture is $W=0 \%$.

A new design of pin-point blasting charge with the improved tamping properties has been proposed for the oriented hole drilling and effectivization of charge blasting. In this context, low-density damping layer of polymer beads is placed between explosive column and tamping (Fig. 5). As experiments show, such a charge provides more qualitative blockage of detonation products within gaseous space as well as increase of total blasting pulse.

Experiments concerning the efficiency of blasting of charges with low-density layer have been carried out within the testing area of Industrial Production Enterprise "Kryvbasvzryvprom" [8]. In the context of clays, ammonite charges No. $6 \mathrm{ZhV}$ with $200 \mathrm{~g}$ to $3 \mathrm{~kg}$ weight were blasted in $26-200 \mathrm{~mm}$ diameter holes and wells at the depth of $0.5-$ $1.5 \mathrm{~m}$. Foamed granulated polystyrol of $0.03-0.08 \mathrm{~kg} / \mathrm{m}^{3}$ was used as the damping layer between tamping and charge. In terms of each series of trial blasts, a diameter, charge height, and depth were constant; only polymeric layer varied (i.e. its height and acoustic stiffness). Explosive efficiency of such charges was estimated according to the dimensions of blasting cone. The experimental results have demonstrated that if parameters of polymeric layer are optimal then blasting efficiency may be increased up to $35 \%$. In terms of height within a hole, low-density layer geometry depends upon physical and mechanical properties of the soil to be blasted, tamping, and of the properties of the layer material itself. 
While analyzing processes taking place while blasting with the use of the above composite tamping, it was supposed that permutation of incompressible particles rather than their deformation happens within shock wave being formed within the damping space material, soil tamping part, and within the rock mass during blasting [9].

Determination of the shock wave parameters within the damping layer should involve velocity of the layer material as well as the shock wave [10]:

$$
\begin{aligned}
& v_{1}=\sqrt{\left(\frac{P_{1}}{\rho_{0 P}}\right) \cdot\left(1-\frac{\rho_{0 P}}{\rho_{P}}\right)}=\left(\frac{3}{8}\right)^{0.5} \cdot D \cdot\left[1-\left(\frac{P_{1}}{P_{H}}\right)^{0.33}\right] ; \\
& P_{1}=\rho_{0 P} \cdot v_{1} \cdot D_{Y 1},
\end{aligned}
$$

where $P_{1}$ is pressure within the shock wave; $D$ is detonation velocity; $P_{H}$ is pressure within the detonation front; $\rho_{0 P}$ and $\rho_{P}$ are the layer material density before detonation front and after it.

Owing to the advance of the extending detonation front over the rock mass in the line of a hole being shaped as for its front in terms of tamping (being provided by means of availability of damping polymeric layer within which the decrease in a shock wave parameters takes place), conditions for compression and consolidation of lower part of tamping material are developed. As a result, the shock wave, moving from the central part of the hole, will be expanded through nonhomogeneous continuum rather than a channel (a hole). That provides more qualitative blockage of explosion products within gaseous cavity since in this case when charge is blasting, tamping material travels simultaneously with upper part of the broken rock mass. Furthermore, advance tamping release is excluded as it is observed when charges with standard tamping are blasted. Moreover, the delay in the process of tamping release factors into pressure drop within the explosion cavity at the expense of extension of its walls decreasing the number of the explosion pulses obtained by the tamping while travelling.

At a first approximation, dependence of relative explosion efficiency $V_{\text {OTN }}$ (ratio between volume released in terms of blasting charges with low-density interlayer and volume released in terms of interlayer-free charges) on the polymer height $\mathrm{h}$ (in terms of the charge diameters) is approached by means of the exponential function:

$$
V_{\text {OTN }}=-A(h-0.5)^{2}+1.35,
$$

where $A$ is coefficient taking into consideration soil properties; it varies within $0.8-2.0$ while passing from dry heavy-textured clay to loose sandy loam.

While selecting optimum height of damping layer, equation (7) is true if $0<h<0.8$. It has also been determined that when the density of soil being blasted increases, the efficiency of such a charge experiences certain decrease; if chambering ratio increases, it increases as well.

It is possible to determine rational height of damping layer in a hole according to the empiric formula:

$$
h=k \cdot d \cdot\left(\frac{C_{B}}{C_{H}}-\frac{C_{B}}{C_{0}}\right)^{-1},
$$

where $k$ is a coefficient involving soil properties; $d$ is a well diameter, $\mathrm{cm} ; C_{B}$ is sound velocity within soil tamping part, $\mathrm{m} / \mathrm{s} ; C_{H}$ is sound velocity within polymeric layer, $\mathrm{m} / \mathrm{s}$; $C_{0}$ is sound velocity within soil mass being blasted, $\mathrm{m} / \mathrm{s}$. 


\section{Conclusions}

Basic advantage of a design of hole charges with low-density interlayer within tamping is as follows: they provide considerable efficiency explosion improvement expressed in the amount of soil outburst per a kilogram of an explosive. In this context, geometry of the damping interlayer turns out to be several times less to compare with, for instance, the dimensions of air gaps in the context of the available designs of release charges making it possible to use the amount of tamping material more productively.

Formation of a low-density material layer within a hole does not involve any processing difficulties being observed while forming charges with air gaps.

It is recommended to place low-density material intermediate tamping layer right after a hole was charged and live primers were inserted with the help of transportation and charging equipment where polymer is foamed within autonomous tanks while exhaust energy utilizing.

The work was carried out in the context of scientific projects "Scientific foundations to form unified system of energy saving and generating in the context of the objects of fuel and energy complex of Ukraine" (State registration No. 0117U001127) and "The development of background technology for environmentally friendly mineral extraction in the context of technogenically loaded mining regions of Ukraine" (State registration No. 0117U001134).

\section{References}

1. Khomenko, O., \& Maltsev, D. (2013). Laboratory Research of Influence of Face Area Dimensions on the State of Uranium Ore Layers Being Broken. Naukovyi Visnyk Natsionalnoho Hirnychoho Universytetu, (2), 31-37.

2. Petlovanyi, M. (2016). Influence of Configuration Chambers on the Formation of Stress in MultiModulus Mass. Mining of Mineral Deposits, (10), 48-54. http://dx.doi.org/10.15407/mining10.02.048

3. Koroviaka, Ye.A. (2008). Obgruntuvannia napriamiv udoskonalennia tekhnologii rozrobky tonkozhylnykh zolotorudnykh rodovychsh Ukrainy. Dnipropetrovsk: Natsionalnyi hirnychyi universytet.

4. Shirin, L.N., Koroviaka, Ye.A., \& Vilianski, V.N. (2004). Formation of the Minimum Width Clearing Area in Case of Small-Hole Breakage Thin-Stranded Steeply Dipping Deposits. Naukovyi Visnyk Natsionalnoho Hirnychoho Universytetu, (11), 11-13.

5. Agoshkov, M.I., Borisov, S.S., \& Boiarski, V.A. (1983). Razrabotka rudnykh i nerudnykh mestorozhdeniy. Moskva: Nedra.

6. Bukrinski, V.A. (1985). Geometriya nedr. Moskva: Nedra.

7. Shirin, L.N., Koroviaka, Ye.A., \& Vilianski, V.N. (2005). Substantiation of the Rational Parameters of the Drill Charge in the Case Breaking thin Steeply Dipping Strands. Naukovyi Visnyk Natsionalnoho Hirnychoho Universytetu, (1), 6-9.

8. Baranov, E.G., Vilianski, V.N., Oberemok, O.N., \& Kurinnoi, V.P. (1990). Influence of Gap Parameters from Porous Low-density Materials on the Efficiency Downhole Charge Explosion. Gornyy zhurnal, (5), 72-76.

9. Liahov, G.M. (1982). Volny v gruntakh i poristykh mnogokomponentnykh sredakh. Moskva: Nedra.

10. Orlenko, L.P. (2004). Fizika vzryva. Moskva: Nauka (Fizmatlit). 